\title{
Adherence to recommended lifestyle modifications and factors associated for hypertensive patients attending chronic follow-up units of selected public hospitals in Addis Ababa, Ethiopia
}

\author{
This article was published in the following Dove Press journal: \\ Patient Preference and Adherence \\ 24 February 2017 \\ Number of times this article has been viewed
}

\author{
Abel Tibebu' \\ Daniel Mengistu ${ }^{2}$ \\ Lemma Negesa' \\ 'School of Nursing and Midwifery, \\ Haramaya University College of \\ Health and Medical Sciences, Harar, \\ ${ }^{2}$ School of Nursing and Midwifery, \\ College of Health Sciences, Addis \\ Ababa University, Addis Ababa, \\ Ethiopia
}

Introduction: One of the most prevalent noncommunicable diseases is hypertension (HTN). The availability of effective antihypertensive medications does not result in the expected outcomes in terms of controlling blood pressure. The rationale for these and other findings of uncontrolled HTN points toward poor adherence. The most neglected causes of uncontrolled HTN are unhealthy lifestyles. Few studies have been conducted to show the gap and magnitude of self-management adherence.

Objective: This study aimed to assess adherence to recommended lifestyle modifications of hypertensive patients undergoing follow-up at chronic follow-up units of public health hospitals in Addis Ababa, Ethiopia, 2016.

Methods: Institutional-based cross-sectional study was conducted in four public health hospitals which were selected by drawing lots. Systematic random sampling was used to select study subjects. The results of the descriptive statistics were expressed as percentages and frequencies. Associations between lifestyle modification and independent variables were analyzed using bivariate and multivariate logistic regression analysis. The study was conducted from February 15, 2016 to April 15, 2016.

Results: The study included 404 respondents with a 97\% response rate; 210 (52\%) were male and the mean age was $54.00 \pm 10.77$ years. The respondents' adherence to lifestyle modifications was $23 \%$. The lifestyle adherence was found to be better in females, patients who had comorbidities, and had been knowledgeable about the disease and was poor among young adult respondents.

Conclusion: The rates of adherence to lifestyle changes were generally found to be low. Educational sessions that especially focus on lifestyle modifications and ongoing support for patients should be designed and studies which assess all the components of self-management should be conducted for comparison among different subgroups.

Keywords: lifestyle modification, adherence, hypertension

\section{Introduction}

The incidence and fatality of noncommunicable diseases are significantly escalating worldwide. According to a recent World Health Organization (WHO) report, these diseases are the preceding causes of morbidity and mortality, more than other causes combined. ${ }^{1}$ Although it has been thought that these diseases were rare in lowand middle-income countries, results of different studies indicate that a significant number of deaths occur due to noncommunicable diseases. ${ }^{1-3}$ In Ethiopia, out of the
Correspondence: Lemma Negesa School of Nursing and Midwifery, Haramaya University College of Health and Medical Sciences, Harar, Ethiopia Tel +25I 923190110

Email lemmitti@gmail.com 
total number of deaths in people aged $<70$ years, $66.5 \%$ (males) and 63.2\% (females) of deaths are accountable to noncommunicable diseases. One of the most common noncommunicable disease affecting a large number of people is hypertension (HTN). According to the WHO, HTN is defined as "a persistent raised systolic or diastolic blood pressure (BP) equal to or more than $140 / 90 \mathrm{mmHg}$ in adults aged 18 years and over." ${ }^{1,4}$ HTN is known to increase the likelihood of occurrence of cardiovascular diseases (CVDs) such as myocardial infarction and congestive heart failure as well as complications like stroke and chronic kidney disease. ${ }^{2}$

Prevalence of HTN around the world is variable, with the lowest prevalence in Australia and northern American countries and the highest prevalence is estimated among southern and northern African as well as middle eastern Asian countries. ${ }^{1}$

The prevalence of HTN is also increasing in Sub-Saharan African countries as well. The disease has been found to be more prevalent among people of urban residence. According to a recent finding, there were $\sim 75$ million adults living with HTN in sub-Saharan Africa. This study estimated that the figure will rise to 125.5 million in the coming $10-15$ years. $^{5-7}$

Findings of studies conducted in Ethiopia show gradual increment in the total number of HTN cases. According to a recent study, HTN was found to be the most prevalent noncommunicable disease with an overall prevalence of $19.1 \% .^{5}$ This increment is attributed to the rise of risk factors including smoking, obesity, harmful use of alcohol, and sedentary lifestyle. , $^{1,5,6}$

The concept of self-management is part of the chronic care model. It was used for the first time in the 1960s with the purpose of highlighting active participation of patients in disease management. Its major aim was to minimize the impact of chronic diseases on physical health status and functioning, allowing individuals to cope with the effects of disease. In addition, it allows patients to tackle the progress of the disease before the emergence of severe complications. Selfmanagement activities are usually performed by individuals and planned together with the healthcare providers. Nurses are key in this process as they play a chief role, in counseling and mentoring patients to achieve the desired outcomes. ${ }^{7}$

One of the most important factors in effective management of HTN is lifestyle modification. It includes patient's ability to adopt dietary approaches to stop HTN (DASH), adopt a low sodium diet, engage in physical activity, moderate alcohol consumption, and cease smoking. ${ }^{8}$
Patients are expected to adhere to these activities in order to alleviate the burden imposed by the disease. The DASH dietary pattern, which has been proved to be effective by multiple randomized controlled trials (RCTs), emphasizes a diet rich in fruits, vegetables, low-fat dairy products, and reduced saturated and total fat. ${ }^{9-11}$

According to the seventh report of the Joint National Committee on Prevention, Detection, Evaluation, and Treatment of High Blood Pressure, majority of patients with HTN are either obese or do not exercise. ${ }^{11}$ This report also gave strong evidence emphasizing the need for smoking cessation for better BP control. ${ }^{12}$

Although the exact pathway of causation of HTN due to consumption of alcohol is not clear, it is well established that there is a strong association between the two variables according to multiple studies based on RCTs. ${ }^{11,13}$ Xin et al also reported a dose-response relationship between alcohol reduction and $\mathrm{BP}$ reduction. ${ }^{14}$

HTN is a chronic illness that needs a person to adhere to lifestyle modifications. ${ }^{15}$ Along with the growth of hypertensive patient comorbidity, mortality rates are also increasing significantly. What is the adherence level to recommended lifestyle modifications and what factors are these associated with? This study was aimed at exploring adherence to recommended lifestyle modifications and its associated factors.

\section{Methodology Study design and sample}

Institutional-based cross-sectional study was conducted from February 15, 2016 to April 15, 2016. Based on the 2007 Census report by the Central Statistical Agency of Ethiopia, Addis Ababa city has a total population of 3,384,569. The study was conducted in chronic follow-up units of Dagmawi Menilik, Tirunesh Beijing, Yekatit 12, and Zewditu memorial hospitals. The size of the study group recruited for the research was calculated using the single population proportion formula. After comparing the proportions for diet-related adherence and exercise adherence, the sample size was calculated considering proportion of exercise adherence to be $0.437,{ }^{16}$ level of confidence $95 \%$, and margin of error 5\%: the sample size was estimated to be 378 . Adding nonresponse rate of $10 \%$, the final sample size was 416 . The target populations were all hypertensive patients who were on follow-up visits at public health hospitals in Addis Ababa, Ethiopia, and the study populations were selected patients who fulfilled the inclusion criteria and were available during the time of data collection. 


\section{Sampling technique}

There are 12 public health hospitals that offer chronic follow-up services in Addis Ababa city. Out of these, four were selected by drawing lots (simple random sampling). The study was conducted in the selected public health hospitals' chronic follow-up units. The number of study units for each unit was proportionally allocated (based on the number of patients reporting per month) and those who were part of the final sample size were selected using systematic random sampling.

\section{Inclusion and exclusion criteria}

Inclusion criteria: all hypertensive patients who were aged $\geq 18$ years and were on medical treatment (antihypertensive) for at least 6 months before commencement of the study were recruited.

Exclusion criteria: patients with cognitive impairment and those who refused to participate were immediately excluded from the study.

\section{Data collection and data quality assurance}

Data were collected through face-to-face interview. The investigator was responsible for the overall management of the project; the development of the final questionnaire; securing participation of the selected patients; and identifying, training and assignment of data collectors and supervisors. The data collectors were four trained diploma nurses who were assigned at each of the four hospitals' chronic follow-up units and were supervised by three BSc nurse professionals. The principal investigator was responsible for overall supervision daily. The purpose of the training was to ensure that all the data collectors had the same information about the study instrument and followed the same interview procedures. The training dealt with the purpose of the study, confidentiality, and how to approach and forward questions to clients. Both the data collectors and supervisors were trained for 2 days on the objective and methodology of the research, data collection approach. The questionnaire was translated to Amharic language and back translated into English by another person to check for consistency.

\section{Variables and measurement}

Dependent variable: adherence to recommended lifestyle modifications.

Independent variables: sociodemographic factors - age, sex, marital status, religion, ethnicity, level of education; personal factors - comorbidities, knowledge about the disease, duration of HTN; behavioral factors - self-efficacy and social factors like support from families and nonfamily members of the society.

A structured interviewer-administered questionnaire was used to collect data on adherence to self-management and associated factors. All the questions were prepared in English and were translated to Amharic by experts who were fluent in both the languages and back translated to English to check consistency.

Lifestyle modification counseling and education were part of routine activity at outpatient follow-up rooms. Adherence to lifestyle modification was assessed in terms of four components including DASH and low sodium diet, regular exercise, minimizing alcohol consumption, and cessation of smoking. Since there were no available standard questionnaires to assess adherence to lifestyle modifications, it was prepared by the principal investigator from review of pertinent literatures. ${ }^{3,15-17}$

The Fast Alcohol Screening Test (FAST; Cronbach's alpha $=0.77$; test-retest reliability $=0.8$ ) which is a short version of the Alcohol Use Disorders Identification Test was used to assess moderation of alcohol consumption. ${ }^{18}$ It included 4 items and a score of 0 for "never", 1 for "less than monthly", 2 for "monthly", 3 for "weekly", and 4 for "daily or almost daily" was given.

The HTN evaluation of lifestyle and management scale which included 14 items was used as a tool to assess respondents' knowledge. ${ }^{19}$ The number of questions was modified to 10 as questions " 7 and 8 " were country specific and questions " 12 and 13" did not meet the study objectives. The tool contains selected response items with the right answer coded as " 1 " and wrong answer as " 0 ".

The Duke Social Support and Stress Scale which includes 12 items was used to assess support gained from family, friends, or significant other members. Responses were coded as follows: "none" $=0$, "some" $=1$, "a lot" $=2$, "yes" $=2$, "no" $=0$, and "there is no such person" $=0$. Blank responses were considered as "0". The support score was calculated by summing the six responses in both sections (family and nonfamily support); based on the reply to the last question, 2 was added to the family or nonfamily support. The total result was divided by 22 and multiplied by 100 to give a $0-100$ score. ${ }^{20}$

The six item Chronic Disease Self-Efficacy Scale was used to measure self-efficacy. The reported internal consistency reliability was $0.91 .{ }^{21}$ Originally, each item contained 
a 10-point scale ranging from "totally unconfident", "unconfident", "not sure", "confident", and "totally confident". The alternatives were modified to five options (completely unconfident was scored 1, unconfident was scored 2, not sure was scored 3, confident was scored 4, and totally confident was scored 5).

\section{Operational definition}

Adherence to lifestyle modifications: respondents who adhere to diet, exercise, smoking, and alcohol consumption-related recommendations.

DASH: a diet rich in fruits, vegetables, low sodium, reduced saturated, and total fat.

Diet-related adherence: in this study, those respondents who reported that they usually or always consumed a diet rich in vegetables, grains, and fruits; rarely or never consumed salt; rarely or never consumed food rich in spices and saturated fat were considered to be adherent.

Exercise-related adherence: respondents who reported to have exercised for $\geq 30 \mathrm{~min}$ per day; at least three times per week.

Smoking-related adherence: respondents who reported to have never smoked or stopped smoking.

Alcohol consumption-related adherence: respondents who reported to have never consumed alcohol or whose overall score on FAST $\leq 3$ were considered adherent to moderation of alcohol consumption.

\section{Data analysis}

Data were checked, cleaned, and fed into Epidata version 3.1 software, and then imported to SPSS version 21.0 (IBM Corporation, Armonk, NY, USA) software for analysis. Incomplete and inconsistent data were excluded from the analysis. Descriptive statistics was used to describe the sample. The results of the descriptive statistics were expressed as percentages and frequencies. Associations between independent and dependent variables were analyzed first using bivariate analysis to identify factors associated with the outcome variable. Those variables which were found to have an association with the outcome variable at $P<0.2$ were used in multivariate logistic regression to test for independent association. The magnitude of the association between different independent variables in relation to the dependent was measured using odds ratios and 95\% confidence interval (CI) and $P$-values $<0.05$ were considered to be statistically significant.

\section{Ethical approval and consent to participate}

Ethical approval of the research proposal was obtained from the Institutional Health Research Ethics Review Committee of Addis Ababa University. Written consent was obtained from the study subjects and an interview was held only with those who gave written consent to participate. The participants could withdraw from the study at any stage.

\section{Results}

\section{Adherence to recommended lifestyle modifications}

The study included 404 respondents with 97\% response rate. In all, 210 (52\%) were male and mean age was $54.00 \pm 10.77$ years. This study found that $23 \%$ of the respondents adhered to all studied lifestyle recommendations; $69.1 \%$ of the respondents adhered to diet-related recommendations; $\sim 85.9 \%$ of participants were nonsmokers or ceased smoking, and $74.8 \%$ of the participants were adherent to moderation of alcohol consumption. Majority $(68.6 \%)$ of the subjects did not engage in regular physical exercise for at least 3 days of the week with a minimum of $30 \mathrm{~min}$ duration. Walking (55.3\%) was the most common physical activity among those who were found to be adherent. The study found that the adherence rates of recommended HTN lifestyle modifications were $>60 \%$ for behaviors related to dietary modification, smoking, and alcohol consumption and were much lower for activities related to physical exercise (Table 1).

In reference to Figure 1, majority $(34.9 \%)$ of the study participants adhered to two components of recommended lifestyle modification followed by those who adhered to three components (29.7\%). Respondents who were non adherent to all components of lifestyle modification were $2.2 \%$, and $10.1 \%$ were adherent to only one type of recommendation.

Table I Adherence to lifestyle recommendations among hypertensive patients attending chronic follow-up units of public health hospitals in Addis Ababa, Ethiopia, $2016(n=404)$

\begin{tabular}{lll}
\hline Variables & Frequency & Percent \\
\hline Adherence to lifestyle modifications & & \\
$\quad$ Adherent & 93 & 23.0 \\
$\quad$ Nonadherent & 311 & 77.0 \\
Diet-related adherence & & \\
$\quad$ Adherent & 277 & 69.1 \\
$\quad$ Nonadherent & 127 & 30.9 \\
Exercise-related adherence & & \\
$\quad$ Adherent & 127 & 31.4 \\
$\quad$ Nonadherent & 277 & 68.6 \\
Smoking & & \\
$\quad$ Ceased & 347 & 85.9 \\
$\quad$ Did not cease & 57 & 14.1 \\
Alcohol consumption & & \\
$\quad$ Moderated & 302 & 74.8 \\
Not moderated & 102 & 25.2 \\
\hline
\end{tabular}




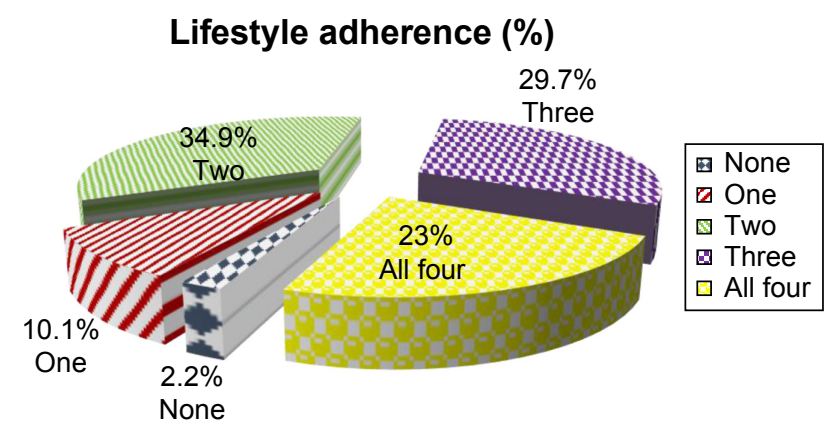

Figure I Percentage of respondents' adherence to the types of lifestyle recommendations in public health hospitals in Addis Ababa, Ethiopia, 2016.

Note: Adherences refer to diet, exercise, smoking, and alcohol consumption.

Overall adherence to all components (diet, exercise, smoking, and alcohol consumption related) was $23 \%$.

\section{Adherence to diet}

Majority of the respondents included fruits, vegetables, grains, and beans in their diet since HTN diagnosis. Almost all respondents rarely or never consumed food that contained high saturated fat and $>60 \%$ of them rarely or never consumed spicy food since diagnosis. Respondents who never or rarely used salt in their food were $12.4 \%$ (Table 2).

\section{Adherence to exercise}

Table 3 shows that $65.1 \%$ of the respondents reported performing physical exercise; of these, the majority (90.1\%) claimed they exercise at least three times per week and an approximately similar number of respondents (90.8\%) confirmed that they engage in an exercise which at least takes $30 \mathrm{~min}$.

In this study, walking was found to be the most common (55.3\%) type of activity among respondents who affirmatively reported on exercise, followed by jogging (28.4\%), and aerobics (16.3\%), respectively (Figure 2).

\section{Smoking cessation}

Table 4 shows that out of the 404 respondents, 265 (65.6\%) never smoked cigarettes. Out of those who were smokers, 57 (41\%) still smoke and $26(45.6 \%)$ did not try to quit smoking.

\section{Moderation of alcohol}

Among all the respondents, 68\% never engaged in harmful drinking ( $\geq 8$ drinks for men and $\geq 6$ for women) on one or more occasions. Among those who consumed similar amount of drinks per single occasion, $21.8 \%$ indulged in it in less than a month, $8.9 \%$ monthly, and $1.4 \%$ weekly or daily.

Out of the 130 respondents who reported that they consumed alcohol, majority (91.5\%) never had a history of inability to remember what happened the night before; $56.9 \%$ and $20.8 \%$ of these respondents confirmed that a relative/ friend/doctor/health worker was concerned about their drinking and advised them to cut down on their drinking on one and more than one occasions, respectively.

\section{Factors associated with adherence to lifestyle modifications}

Table 5 shows the demographic, personal, social, and behavioral factors associated with lifestyle modification adherence. After controlling possible confounding effects of other covariates, sex, age, work status, time since diagnosis, comorbidity, knowledge about the disease, self-efficacy, and social support were found to be significantly associated with lifestyle adherence. Female respondents were found two times more likely to be adherent to recommended lifestyle modifications when compared to their male counterparts (adjusted odds ratio, $\mathrm{AOR}=2.29,95 \% \mathrm{CI}$ : 1.10, 4.75). Unemployed respondents were found less likely to be adherent than the employed ones. Respondents in the old aged adult group were found to be six times more adherent than respondents in the young adult age group $(\mathrm{AOR}=5.72,95 \% \mathrm{CI}: 1.16$, 28.14). Longer time since diagnosis was also found to be significantly associated compared to shorter duration since diagnosis. Respondents with no comorbidities were found to be $76 \%$ less likely to be adherent than those who had them $(\mathrm{AOR}=0.24,95 \% \mathrm{CI}: 0.11,0.50)$. Those respondents who had good knowledge were 13 times more likely to be adherent (AOR $=13.27,95 \%$ CI: 4.12, 42.72) compared to the non-knowledgeable respondents. The participants who had good self-efficacy were found four times more likely to be adherent than those who had poor self-efficacy.

Table 2 Response of participants on diet-related recommendations in chronic follow-up units of public health hospitals in Addis Ababa, Ethiopia, $2016(n=404)$

\begin{tabular}{|c|c|c|c|c|}
\hline Variables & Never & Rarely & Usually & Always \\
\hline $\begin{array}{l}\text { How often do you include fruits, vegetables, grains, and beans in } \\
\text { your diet after diagnosis? }\end{array}$ & $7(1.7 \%)$ & II 3 (28\%) & $240(59.4 \%)$ & $44(10.9 \%)$ \\
\hline How often do you consume foods that contain high saturated fat? & $85(21 \%)$ & $299(74 \%)$ & $18(4.5 \%)$ & $2(0.5 \%)$ \\
\hline How often do you consume spicy foods since being diagnosed? & $66(16.3 \%)$ & $192(47.5 \%)$ & |3| (32.4\%) & $15(3.7 \%)$ \\
\hline How often do you consume salt in your food? & $19(4.7 \%)$ & $31(7.7 \%)$ & $109(27 \%)$ & $245(60.6 \%)$ \\
\hline
\end{tabular}


Table 3 Response of participants on exercise-related issues in chronic follow-up units of public health hospitals of Addis Ababa, Ethiopia, 2016

\begin{tabular}{|c|c|c|}
\hline Variables & Frequency & Percent \\
\hline \multicolumn{3}{|c|}{ Do you perform physical exercise at all? } \\
\hline Yes & $|4|$ & 65.1 \\
\hline No & 263 & 34.9 \\
\hline \multicolumn{3}{|c|}{ How often do you exercise? } \\
\hline$<3$ times per week & 14 & 9.9 \\
\hline$\geq 3$ times per week & 127 & 90.1 \\
\hline \multicolumn{3}{|c|}{ For how long do you exercise per session? } \\
\hline$<30$ min per day & 13 & 9.2 \\
\hline$\geq 30$ min per day & 126 & 90.8 \\
\hline
\end{tabular}

Having support from the society was also associated with adherence to lifestyle modifications as the respondents who had support were $\sim 11$ times more likely to be adherent (AOR $=10.70,95 \%$ CI: 4.59, 24.96).

\section{Discussion}

HTN is a chronic condition that leads to serious complications if the person cannot control and manage BP. HTN management consists of two main parts; pharmacological therapy and lifestyle modifications. ${ }^{1}$ The mean age of the participants in this study was $54 \pm 10.77$ years, which emphasizes that the disease mostly affects individuals in their late middle adulthood and above. Out of the 404 respondents, 52\% were male consolidating the results of different studies and asserting that the prevalence of HTN is higher in males than females. ${ }^{2,15,22,23}$ This study tried to assess the prevalence of adherence to self-management activities among hypertensive patients in terms of adherence to antihypertensive medications and lifestyle modifications. The overall adherence (including diet, exercise, smoking cessation, and moderation of alcohol consumption) in this study was only $23 \%$. A Saudi study found that only $4.2 \%$ of respondents were adherent to all types of lifestyle recommendations. ${ }^{24}$ This discrepancy could be explained by methodological factors where the latter

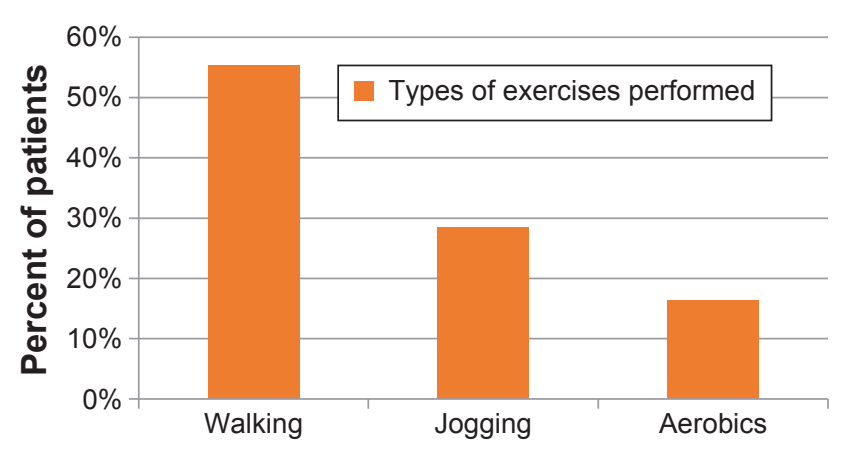

Figure 2 Types of activities performed by respondents attending chronic follow-up units of public health hospitals of Addis Ababa, Ethiopia, 2016.
Table 4 Response of participants on cigarette smoking among hypertensive patients attending chronic follow-up units of public health hospitals in Addis Ababa, Ethiopia, 2016

\begin{tabular}{lll}
\hline Variables & Frequency & Percent \\
\hline Have you ever smoked cigarettes? & & \\
$\quad$ Yes & 139 & 34.4 \\
$\quad$ No & 265 & 65.6 \\
Do you still smoke cigarettes? & 57 & \\
$\quad$ Yes & 82 & 41 \\
No & & 59 \\
Have you tried to quit smoking? & 31 & \\
$\quad$ Yes & 26 & 54.4 \\
No &
\end{tabular}

included a small sample of only male participants. This study asserted diet-related adherence by consuming food low in sodium, fat, spice levels; including more fruits, vegetables, grains, and beans in the diet; and reading nutritional facts on food labels. The prevalence of diet-related adherence in this study was $69.1 \%$. This is comparable to a study carried out in Addis Ababa where $64.7 \%$ of the respondents were found to be adherent. In contrast, a study in Bangladesh found that majority $(65.5 \%)$ of the study participants did not follow a special dietary modification. ${ }^{9}$ The discrepancy between the two local studies and the study from Bangladesh could be due to the difference between the dietary habits between the two countries and residence of study participants.

In this study, exercise-related adherence was $31.4 \%$. Similar studies conducted in Israel and China found $47.7 \%$ and $51.9 \%$ adherence, respectively. ${ }^{25,26}$ The possible explanation could be related to cultural differences and lack of organized setup in living areas in developing countries like Ethiopia. The finding of this study was almost similar to a study from Turkey where $31 \%$ of the participants were adherent to exercise. A study from Bangladesh considered performance of regular exercise as one of the activities never practiced $(77 \%) .{ }^{15}$ This could be due to the rural resident respondents in Bangladesh. A local study in one public health hospital in Addis Ababa found 43.7\% adherence to exercise. ${ }^{17}$ This consolidates reports asserting sedentary lifestyle is increasing in low- and middle-income countries like Ethiopia causing an escalation in the prevalence of chronic diseases like HTN. ${ }^{27,28}$ Smoking is one of the important risk factors for CVDs including HTN. A large portion (85.9\%) of respondents in this study had ceased smoking or never smoked before. Findings related to cessation of smoking are in line with studies conducted in Bangladesh, China, Turkey, and Israel, where majority of the respondents were found to be adherent. ${ }^{15,25,26,29}$ In this study, $74.8 \%$ of the respondents moderated their alcohol consumption. Almost all the 
Table 5 Association of adherence to lifestyle modifications by selected characteristics, among hypertensive patients in public health hospitals of Addis Ababa, Ethiopia, 2016

\begin{tabular}{|c|c|c|c|c|}
\hline \multirow[t]{2}{*}{ Variables } & \multicolumn{2}{|c|}{ Lifestyle adherence } & \multirow[t]{2}{*}{ COR $(95 \% \mathrm{Cl})$} & \multirow[t]{2}{*}{ AOR $(95 \% \mathrm{Cl})$} \\
\hline & $\begin{array}{l}\text { Adherent } \\
\mathbf{N}(\%)\end{array}$ & $\begin{array}{l}\text { Nonadherent } \\
\mathbf{N}(\%)\end{array}$ & & \\
\hline \multicolumn{5}{|l|}{ Sex } \\
\hline Male & $164(52.7)$ & $46(49.5)$ & 1.00 & 1.00 \\
\hline Female & $147(47.3)$ & $47(50.5)$ & $\mathrm{I} . \mathrm{I} 4(0.72, \mathrm{I} .8 \mathrm{I})$ & $2.290(\mathrm{I} .10,4.75)^{*}$ \\
\hline \multicolumn{5}{|l|}{ Age, years } \\
\hline $21-39$ & $5(5.4)$ & $28(9)$ & & 1.00 \\
\hline $40-59$ & $61(65.6)$ & $177(56.9)$ & $1.93(0.71,5.22)$ & $2.24(0.62,8.06)$ \\
\hline$>60$ & $27(29.0)$ & $106(34.1)$ & $\mathrm{I} .43(0.50,4.04)$ & $5.72(1.16,28.13)^{*}$ \\
\hline \multicolumn{5}{|l|}{ Marital status } \\
\hline Not cohabited & $20(2 \mid .5)$ & $\mid 28(4 \mid .2)$ & 1.00 & 1.00 \\
\hline \multicolumn{5}{|l|}{ Education } \\
\hline No formal education & $8(8.6)$ & $135(43.4)$ & 1.00 & 1.00 \\
\hline $\begin{array}{l}\text { Formal education } \\
\text { Work status }\end{array}$ & $85(91.4)$ & $176(56.6)$ & $8.15(3.82,17.40)$ & $2.19(0.63,7.62)$ \\
\hline Employed & $78(83.9)$ & $179(57.6)$ & 1.00 & 1.00 \\
\hline Unemployed & $15(16.1)$ & $132(42.4)$ & $0.26(0.14,0.47)$ & $0.18(0.05,0.60)^{*}$ \\
\hline \multicolumn{5}{|l|}{ Time since diagnosis } \\
\hline$<2$ years & $3(3.2)$ & $46(14.8)$ & 1.00 & 1.00 \\
\hline $2-4$ years & $45(48.4)$ & $112(36.0)$ & $6.16(1.82,20.88)$ & $7.14(1.56,32.78)$ \\
\hline$\geq 4$ years & $45(48.4)$ & $153(49.2)$ & $4.51(1.34,15.19)$ & $4.59(1.00,20.97)^{*}$ \\
\hline \multicolumn{5}{|l|}{ Comorbidities } \\
\hline Yes & $69(74.2)$ & $155(49.8)$ & 1.00 & 1.00 \\
\hline No & $24(25.8)$ & $156(50.2)$ & $0.35(0.21,0.58)$ & $0.24(0.11,0.50)^{* *}$ \\
\hline \multicolumn{5}{|l|}{ Knowledge } \\
\hline Poor knowledge & $4(4.3)$ & I7| (55.0) & 1.00 & 1.00 \\
\hline Good knowledge & $89(95.7)$ & $140(45.0)$ & $27.18(9.738,75.85)$ & $13.26(4.12,42.7 \mid)^{* *}$ \\
\hline \multicolumn{5}{|l|}{ Self efficacy } \\
\hline Good efficacy & II (II.8) & $139(44.7)$ & 1.00 & 1.00 \\
\hline Poor efficacy & $82(88.2)$ & $172(55.3)$ & $6.02(3.09$, I I.75) & $3.92(1.61,9.56)^{*}$ \\
\hline \multicolumn{5}{|l|}{ Social support } \\
\hline Not supported & $9(9.7)$ & 191 (6I.4) & 1.00 & 1.00 \\
\hline Supported & $84(90.3)$ & $120(38.6)$ & I4.86 (7.20, 30.65) & $10.70(4.59,24.96)^{* *}$ \\
\hline
\end{tabular}

Notes: *AOR is statistically significant at $P<0.05$, **AOR is statistically significant at $P<0.001$.

Abbreviations: $\mathrm{AOR}$, adjusted odds ratio; $\mathrm{COR}$, crude odds ratio; $\mathrm{Cl}$, confidence interval.

participants (99.1\%) of a study in Bangladesh stated that they never drank alcohol. ${ }^{15}$ This discrepancy could be explained by cultural and religious factors. This study identified that adherence to recommended lifestyle modification was low and this directly affected patient treatment outcome. Health care providers need to focus on counseling and instructing patients about the importance of adhering to recommended lifestyle changes. The study did not include hypertensive patients attending follow-up in private health facilities. The cross sectional study design used could not express cause and effect relationships. Also, research methodologies involving self-reported measures depend largely on individuals' memory, and recall bias may exist.

\section{Conclusion}

This study found $23 \%$ adherence to recommended lifestyle modifications. This shows that adherence to lifestyle modification rates are very low. The factors impeding or enhancing the outcome variables were thoroughly analyzed. Comorbidity, knowledge about the disease, self-efficacy, and social support were found to be significantly associated with adherence to recommended lifestyle modifications. Relatively unstudied predictors such as knowledge about the disease, self-efficacy, and social support were also found to be significantly associated with adherence to recommended lifestyle modification.

\section{Acknowledgments}

The authors would like to thank the participants of this study for their cooperation and Addis Ababa University, School of Nursing and Midwifery for their support and facilitation.

\section{Disclosure}

The authors report no conflicts of interest in this work. 


\section{References}

1. Alwan A. Global Status Report on Noncommunicable Diseases 2010. World Health. Geneva, Switzerland: World Health Organization; 2010: 176. Available from: http://whqlibdoc.who.int/ publications/2011/9789240686458_eng.pdf. Accessed March 20, 2016.

2. Whelton PK, He J, Muntner P. Prevalence, awareness, treatment and control of hypertension in North America, North Africa and Asia. J Hum Hypertens. 2004;18:545-551.

3. Adult Hypertension Clinical Practice Guidelines: Managing High Blood Pressure. New York; 2013. Available from: https://millionhearts.hhs. gov/files/NYC_HHC_Hypertension_Protocol.pdf. Accessed March 20, 2016.

4. Angaw K, Dadi AF, Alene KA. Prevalence of hypertension among federal ministry civil servants in Addis Ababa, Ethiopia: a call for a workplace-screening program. BMC Cardiovasc Disord. 2015;15:76.

5. Nshisso LD, Reese A, Gelaye B, Lemma S, Berhane Y, Williams MA. Prevalence of hypertension and diabetes among Ethiopian adults. Diabetes Metab Syndr. 2012;6(1):36-41.

6. Ogah OS, Rayner BL. Recent advances in hypertension in sub-Saharan Africa. Heart. 2013;303227:1-8.

7. Warren-Findlow J, Seymour RB, Shenk D. Intergenerational transmission of chronic illness self-care: results from the caring for hypertension in African American Families Study. Gerontologist. 2011; 51(1):64-75.

8. Douglas BM, Howard EP. Predictors of self-management behaviors in older adults with hypertension. Adv Prev Med. 2015;2015:960263.

9. Azadbakht L, Fard NRP, Karimi M, et al. Effects of the dietary approaches to stop hypertension (DASH) eating plan on cardiovascular risks among type 2 diabetic patients: a randomized crossover clinical trial. Diabetes Care. 2011;34(1):55-57.

10. Appel LJ, Brands MW, Daniels SR, Karanja N, Elmer PJ, Sacks FM. Dietary approaches to prevent and treat hypertension a scientific statement from the American Heart Association. Hypertension. 2006;47(2): 296-308.

11. DHHS. The Seventh Report of the Joint National Committee on Prevention, Detection, Evaluation, and Treatment of High Blood Pressure. 2004;42:1206-1252.

12. Registered Nurses' Association of Ontario. Nursing Management of Hypertension: Nursing Best Practice Guidelines. Ontario, Canada; 2005.

13. Appel LJ. ASH position paper: dietary approaches to lower blood pressure. J Am Soc Hypertens. 2010;4(2):79-89.

14. Xin X, He J, Frontini MG, Ogden LG, Motsamai OI, Whelton PK. Effects of alcohol reduction on blood pressure: a meta-analysis of randomized controlled trials. Hypertension. 2001;38(5):1112-1117.

15. Akhter N. Self-Management among Patients with Hypertension in Banagladesh. Prince of Songkla University, Banagladesh; 2010.
16. Hareri HA, Abebe M, Asefaw T. Assessments of adherence to hypertension managements and its influencing factors among hypertensive patients attending black lion hospital chronic follow up unit, Addis Ababa, Ethiopia - a cross-sectional study. Int J Pharm Sci Res. 2013; 4(3):1086-1095.

17. Al-solaiman Y, Jesri A, Mountford WK, Lackland D, Zhao Y, Egan BM. Dash lowers blood pressure in obese hypertensives beyond pottasium, magnesium and fiber. J Hum Hypertens. 2010;24(4):237-246.

18. Health Development Agency. Manual for the Fast Alcohol Screening Test (FAST): Fast screening for alcohol problems. Development. 2002;12(3):1-14

19. Schapira MM, Fletcher KE, Hayes A, et al. The development and validation of the hypertension evaluation of lifestyle and management knowledge scale. J Clin Hypertens. 2012;14(7):461-466.

20. Mcdowell I. Measuring health: a guide to rating scales. Stat Med. 1989;8:1308-1309.

21. Stanford Patient Education Research Center. Self-efficacy for managing chronic disease 6-item scale. Available from: http://patienteducation. stanford.edu/research/secd6.html. Accessed March 20, 2016.

22. Gudina K, Bonsa F, Gudina EK, Hajito KW. Original article prevalence of hypertension and associated factors in Bedele town, southwest Ethiopia. Ethiop J Heal Sci. 2014;24(6):21-26.

23. Okwuonu CG, Ojimadu NE, Okaka EI, Akemokwe FM. Patient-related barriers to hypertension control in a Nigerian population. Int J Gen Med. 2014;7:345-353.

24. Elbur AI. Level of adherence to lifestyle changes and medications among male hypertensive patients in two hospitals in taif; Kingdom of Saudi Arabia. Int J Pharm Pharm Sci. 2015;7(4):168-172.

25. Danaei G, Finucane MM, Lin JK, et al. National, regional, and global trends in systolic blood pressure since 1980: systematic analysis of health examination surveys and epidemiological studies. Lancet. 2011; 377(9765):568-577.

26. $\mathrm{Hu} \mathrm{H}, \mathrm{Li} \mathrm{G}, \mathrm{Arao} \mathrm{T}$. Prevalence rates of self-care behaviors and related factors in a rural hypertension population: a questionnaire survey. Int J Hypertens. 2013;2013:526949.

27. Opie LH, Seedat YK. Hypertension in Sub-Saharan African populations. Circulation. 2005;112(23):3562-3568.

28. Uzun S, Kara B, Yokuşoğlu M, Arslan F, Yilmaz MB, Karaeren H. The assessment of adherence of hypertensive individuals to treatment and lifestyle change recommendations. Anadolu Kardiyol Derg. 2009;9: 102-109.

29. Heymann AD, Gross R, Tabenkin H, Porter B, Porath A. Factors associated with hypertensive patients' compliance with recommended lifestyle behaviors. Isr Med Assoc J. 2011;13(9):553-557.
Patient Preference and Adherence

\section{Publish your work in this journal}

Patient Preference and Adherence is an international, peer-reviewed, open access journal that focuses on the growing importance of patient preference and adherence throughout the therapeutic continuum. Patient satisfaction, acceptability, quality of life, compliance, persistence and their role in developing new therapeutic modalities and compounds to optimize

\section{Dovepress}

clinical outcomes for existing disease states are major areas of interest for the journal. This journal has been accepted for indexing on PubMed Central The manuscript management system is completely online and includes a very quick and fair peer-review system, which is all easy to use. Visit http://www. dovepress.com/testimonials.php to read real quotes from published authors. 